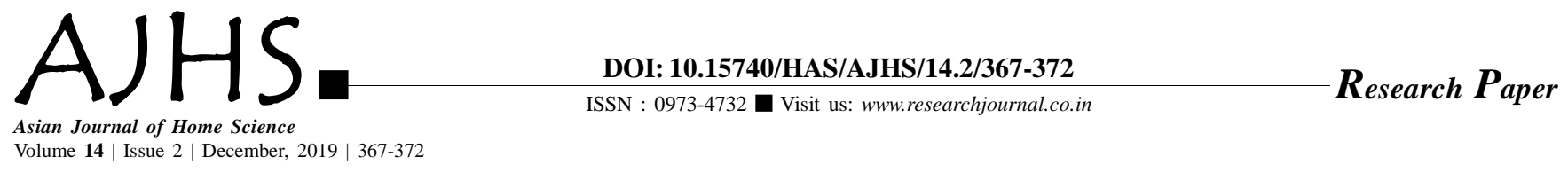

\title{
Buying preferences followed by homemakers while purchasing selected household goods
}

\author{
Kushavarta M. Gadge and Madhuri S. Kulkarni
}

Received: 27.09.2019; Revised: 23.10.2019; Accepted: 07.11.2019

See end of the paper for authors' affiliations

Madhuri S. Kulkarni

Department of Resource

Management and Consumer

Science, College of Community

Science, Vasantrao Naik

Marathwada Krishi Vidyapeeth,

Parbhani (M.S.) India

Email : profmadhuri@gmail.com
ABSTRACT : The research on buying preferences followed by homemakers while purchasing selected household goods was conducted through questionnaire investigation by personal interview method among 150 randomly selected full time homemakers. Scales of preferences for purchase of grocery, clothes, furniture, bed linen and electrical appliances developed by Revanwar et al. (2009) were used to assess the preferences of selected homemakers while buying these items. Statistical analysis was carried out by applying ' $Z$ ' test and ANOVA technique. The results of the study indicated that majority of the homemakers were between the age group of 25 and 35 years and school educated. It was noticed that quality secured highest rank by homemakers while buying grocery, clothes and electrical appliances whereas material secured highest rank for purchase of bed linen and design secured highest rank for purchase of furniture. Statistical analysis with ANOVA indicated significantly higher differences in preferential scores for various factors while buying selected household goods.

GEY WORDS: Household goods, Homemaker, Buying preferences

- HOW TO CITE THIS PAPER : Gadge, Kushavarta M. and Kulkarni, Madhuri S. (2019). Buying preferences followed by homemakers while purchasing selected household goods. Asian J. Home Sci., 14 (2) : 367-372, DOI: 10.15740/HAS/AJHS/14.2/367-372. Copyright@ 2019: Hind Agri-Horticultural Society. 